\title{
EDUCAÇÃO FÍSICA ESCOLAR E ESTUDANTES COM DEFICIÊNCIA MÚLTIPLA SENSORIAL VISUAL EM TEMPOS DE COVID-19
}

\section{SCHOOL PHYSICAL EDUCATION AND STUDENTS WITH MULTIPLE DISABILITIES AND VISUAL IMPAIRMENTS IN COVID-19 TIME}

\author{
Flavia Daniela dos Santos Moreira ${ }^{25}$ \\ Arlindo Fernando Paiva de Carvalho Junior ${ }^{26}$
}

\section{Resumo}

A Deficiência Múltipla Sensorial Visual é uma condição heterogênea que serve para designar pessoas cegas ou com baixa visão associada a outras deficiências. No presente artigo analisamos os desafios e possibilidades vivenciados por esses estudantes no contexto da pandemia de Covid-19. Essa análise ocorreu a partir de nossas experiências enquanto professores e apoiados na concepção metodológica de cunho qualitativo, seguindo a estratégia das narrativas. Propomos atividades para serem desenvolvidas por esses estudantes e suas famílias em casa, orientadas pelo professor de Educação Física. Concluímos que essas atividades, desenvolvidas em parceria com familiares, podem contribuir satisfatoriamente com o desenvolvimento integral desses estudantes.

Palavras-chave: Deficiência Múltipla Sensorial Visual. Educação Física. Pandemia. Covid-19

\begin{abstract}
Multiple Disability and Visual Impairment is a heterogeneous condition that serves to designate people who are blind or have low vision associated with other disabilities. In the present article, we analyze the challenges and possibilities experienced by these students in the context of the Covid-19 pandemic. This analysis was based on our experiences as teachers and supported by a qualitative methodological conception, following the narrative strategy. We propose activities to be developed by these students and their families at home, guided by the Physical Education teacher. We
\end{abstract}

\footnotetext{
${ }^{25}$ Professora do Instituto Benjamin Constant (IBC). Doutora em Educação pela Universidade do Estado do Rio de Janeiro (UERJ). Pesquisadora de Pós-Doutorado em Educação na UERJ. Coordenadora do Laboratório de Comunicação Alternativa Tátil - LABCÁTIL-IBC. E-mail: labcatil@ibc.gov.br. Orcid: https://orcid.org/0000-0003-3262-6289

${ }^{26}$ Professor do Instituto Benjamin Constant (IBC). Especialista em Docência no Ensino Básico e Superior, EFE, Educação Tecnológica, Inclusão e em Planejamento, Implementação e Gestão da EAD Mestre em Ciências da Atividade Física Doutorando em Educação - UNIRIO/EDC - España. Coordenador GPCECI. Orcid: https://orcid.org/0000-0002-5041-8232
} 


\section{RevistAleph}

conclude that these activities, developed in partnership with family members, can contribute satisfactorily to the integral development of these students.

Keywords: Multiple Disability and Visual Impairment. Fisic Education. Pandemic. Covid19.

\section{Introdução}

A crise sanitária ocasionada pela pandemia do coronavírus acarretou uma situação sem precedentes em todas as esferas da vida, inclusive na educação. Em meio a esse cenário, o sistema educacional brasileiro se viu forçado a se reestruturar, incluindo uma intensa discussão acerca das formas e possibilidades de organização da educação especial.

O imperativo de mudar a educação presencial para a educação na modalidade do ensino remoto, impôs inúmeros desafios e fez sobressair, ainda mais, as desigualdades sociais para acessar os recursos tecnológicos. Booth e Ainscow (2000) são eloquentes ao mencionar que a escola real, em qualquer tempo, reflete uma complexa relação de fatores inclusivos e excludentes que giram em torno de indivíduos e grupos de estudantes.

Tornou-se evidente que os estudantes mais vulneráveis, incluindo aqueles com deficiência, eram os mais prejudicados. Dentre estes estudantes encontram-se aqueles com deficiência múltipla sensorial visual (DMSV). Desta maneira, praticar a inclusão em tempos de pandemia revela-se como processo que se constrói de forma contínua, variando conforme os vieses sociais (SILVA, 2008).

Importa dizer que as medidas adotadas pelo governo para dar continuidade ao ensino, seja por meio de aulas síncronas (ao vivo/em tempo real) ou aulas assíncronas (sem a interação em tempo real), fez-se necessária para assegurar o distanciamento físico e conter o risco de contágio.

Em meio a tudo isso, os professores de Educação Física, que trabalham com a cultura corporal - do movimento e em movimento - se viram reféns de uma situação angustiante: a impossibilidade de interagir e se relacionar com o corpo desses estudantes em função do distanciamento físico. 


\section{RevistAleph}

Diante disso, este texto estrutura-se por meio de uma narrativa, a partir de nossa percepção, acerca de algumas dificuldades e possibilidades referentes ao ensino de estudantes com DMSV em tempos de distanciamento físico. Por essa razão, nosso objetivo consiste em apresentar algumas atividades que possam contribuir com a aprendizagem e o desenvolvimento desses estudantes, levando em consideração suas características e necessidades.

Inicialmente abordamos as questões referentes à pandemia, com uma visão panorâmica a respeito dos efeitos dessa situação no processo de ensino e aprendizagem para os estudantes em situação de desvantagem, especialmente aqueles que apresentam a deficiência visual associada a outras deficiências. Em seguida, apresentamos alguns pontos relativos ao perfil desses estudantes. E na sequência, sugerimos atividades específicas que podem ser orientadas pelos professores de Educação Física e que consideram as condições excepcionais de aprendizagem desses estudantes no cenário atual.

\section{Concepção Metodológica}

A pandemia de coronavírus no Brasil, impulsionou a conexão entre professores e estudantes a partir do ensino em tempo real, com as chamadas aulas síncronas e sem a interação em tempo real, por meio das aulas ou atividades assíncronas.

Considerando que os estudantes com deficiência múltipla sensorial visual precisam do tato para adquirir informações do meio, apresentamos-de forma reflexiva e crítica - nossas percepções acerca dessa realidade em forma de narrativa, tendo como foco as questões educacionais referentes a esses estudantes.

Nosso intuito consiste em propor algumas atividades colaborativas que possam contribuir com a prática de professores de Educação Física. Sob a perspectiva qualitativa, nos apropriamos da estratégia da narrativa para compreender e expressar nossas considerações acerca do contexto educacional nesse cenário pandêmico, suas transformações e movimentos e seus impactos na educação de estudantes com DMSV. 


\section{RevistAleph}

Por essa razão, este texto é narrado na primeira pessoa do plural para realçar a narrativa de dois professores que se apoiam nas experiências cotidianas e na literatura especializada da área. Haja vista que

[...] as narrativas de vida nunca serão uma verdade sobre os fatos vividos e, sim, uma versão possível, que thes atribuem os que vivenciaram os fatos, a partir dos dados de sua biografia, de sua experiência, de seu conhecimento e de sua visão do futuro (MINAYO, 2014, p. 154).

Considerando a complexidade da realidade, não a narraremos na íntegra, mas sim parte dela: a parte que nos envolve, que nos confronta e nos impulsiona, enquanto professores-pesquisadores, a refletir sobre as tensões e implicações desta pandemia na educação dos estudantes com DMSV. Pois acreditamos que as práticas educacionais inclusivas devem estar presentes no bojo do desenvolvimento da escola e além dos muros escolares.

Práticas educacionais inclusivas devem favorecer a aprendizagem e a participação de TODOS os alunos (SILVA, 2008). Sob o viés da perspectiva inclusiva, consideramos que todos os estudantes têm direito à prática de atividades físicas sem discriminação, com igualdade de oportunidades, respeito às diferenças e, sobretudo, valorização de seus pontos fortes (SILVA, 2008).

\section{O Contexto da Pandemia no Brasil}

Em comparação com o cenário mundial, o Brasil foi um dos países mais afetados pela propagação da COVID-19 com consequências devastadoras em todo território nacional.

Este vírus, identificado como SARS-CoV- ${ }^{27}$, foi descoberto em novembro de 2019 na cidade de Wuhan, na província de Hubei - na China (FUNDAÇÃO OSWALDO

\footnotetext{
${ }^{27}$ De acordo com a OMS (2020), “Os coronavírus são uma grande família de vírus que podem ocasionar doenças em humanos e animais". Em humanos, podem causar infecções respiratórias leves a doenças mais graves, como a Síndrome Respiratória do Oriente Médio (MERS) e a Síndrome Respiratória Aguda Grave (SARS). Em 2019, houve a transmissão do novo coronavírus (SARS-CoV-2) que foi identificado em
} 


\section{RevistAleph}

CRUZ, 2020). Trata-se de uma nova cepa de vírus que ocasiona um quadro clínico variando de infecções assintomáticas a quadros muito graves de saúde (MINISTÉRIO DA SAÚDE, 2020).

O fato é que esse vírus se expandiu rapidamente no cenário mundial, provocando uma crise sanitária global e forçando a Organização Mundial de Saúde declarar pandemia em 11 de março de 2020. A falta de conhecimento a respeito da COVID-19 e dos seus riscos à saúde humana, fez com que as autoridades de saúde demorassem a tomar providências para conter sua proliferação, o que causou milhares de mortes por todo o mundo.

No Brasil, o vírus foi identificado pelas autoridades em fevereiro de 2020 e, já em março, diversos setores sociais começaram a parar em função do distanciamento físico. Dentre esses setores, encontra-se o sistema educacional, que teve suas aulas suspensas com o objetivo de evitar a transmissão da doença e preservar vidas.

Pouco tempo depois da suspensão das aulas presenciais, diferentes sistemas de ensino, influenciados por tensões causadas pela política neoliberal, passaram a ofertar a educação à distância de forma emergencial, despreparada e não planejada, chamando-a de ensino remoto, termo popularizado com repercussão e visibilidade em função desta pandemia.

Essa política de educação conteudista com saberes pré-estabelecidos, que necessitam ser transmitidos a todo custo aos estudantes, independente da situação e realidade vivida, é própria de um modelo de educação neoliberal que está a favor dos interesses dos grandes empresários e instituições financeiras como a Organização para Cooperação e Desenvolvimento Econômico (OCDE), que influenciou, por exemplo, a construção da Base Nacional Curricular Comum com apoio dos chamados reformadores empresariais da educação (FREITAS, 2012).

Primeiro, os professores sofreram pressão para voltarem a trabalhar na modalidade de educação à distância, e num segundo momento, foram pressionados a

Wuhan na China causando uma pandemia global. Mais informações: https://www.who.int/emergencies/diseases/novel-coronavirus-2019 


\section{RevistAleph}

voltarem a trabalhar presencialmente em meio ao caos instalado pelo descontrole da pandemia.

Os interesses econômicos são postos à frente da vida ${ }^{28}$. Mbembe (2018) chama esta situação de necropolítica. Essa política, que afeta fortemente o sistema educacional brasileiro, pôde ser vista também através da campanha "O Brasil não pode parar" 29 lançada pelo governo federal em plena pandemia, incentivando as pessoas saíssem às ruas para aquecer o funcionamento dos comércios e a volta da economia (LEMOS; ASSIS, 2020).

Diante dessa realidade, em uma sociedade marcada pela exclusão histórica das pessoas com deficiência, o vírus SARS-CoV-2 veio para acentuar ainda mais as desigualdades sociais e o processo ensino-aprendizagem tornou-se questionável por parte dos educadores, gestores e familiares.

Pensar uma educação inclusiva dentro deste formato, implica considerá-la como um processo que se estrutura continuamente. Silva (2008) ressalta que não existe um estado de inclusão permanente. A inclusão é um devir que se desenvolve ao longo de um continuum e, por isso, precisa ser revista com frequência para evitar a instalação dos mecanismos de exclusão social (SILVA, 2008).

Destarte, o impacto da COVID-19 afeta desproporcionalmente os diferentes segmentos sociais. Para Santos (2020), as pessoas com deficiência já sofriam com o patriarcado, o capitalismo e o colonialismo, e agora também com o capacitismo, que seria justamente o não atendimento das necessidades dos estudantes com deficiência nesse período de pandemia, deixando-os à margem desse processo.

No caso das crianças com DMSV, com características e necessidades excepcionais, essa exclusão se torna ainda mais notável, pois não se limita apenas em

\footnotetext{
${ }^{28} \mathrm{Em} 19$ de setembro de 2020, aproximadamente sete meses após o primeiro caso no Brasil, o Ministério da Saúde divulgou os seguintes dados: o total de 136.532 óbitos, 4.528 .240 casos confirmados, 571.613 pessoas em observação, 3.820.095 casos de pessoas recuperadas, em uma população de 210.134 .852 habitantes, em uma média de mais de 700 mortes por dia.

${ }^{29} \mathrm{~A}$ campanha deixou de ser veiculada pelo governo por determinação da Justiça Federal do Rio de Janeiro (BERTONI, 2020).
} 


\section{RevistAleph}

acessar ferramentas de acessibilidade. Muitos desses estudantes se comunicam por meio de modalidades informais e enfrentam dificuldades para acessar informações de forma adequada através do ensino remoto.

Em meio a esse contexto, imposto por essa crise sanitária e agravada pela crise política brasileira ${ }^{30}$, o sistema educacional, pressionado pela volta do crescimento econômico estabelece um ensino remoto padronizado desconsiderando as necessidades plurais dos estudantes. E nesse caso, os estudantes com DMSV são um dos grupos mais afetados, pois não dependem apenas da promoção de acessibilidades virtuais, que já não são ofertadas. Seus familiares precisam de orientações e apoios adequados para que possam continuar as ações pedagógicas durante esse período.

\section{O estudante com deficiência múltipla sensorial visual (DMSV)}

As crianças com DMSV são aquelas que apresentam a cegueira ou a baixa visão, associada à deficiência intelectual, física ou a distúrbios globais do desenvolvimento e déficit de comunicação (KEIL, 2003; ARGYROPOULOS; THYMAKIS, 2014). Esse conjunto de características serve para representar estudantes com condições amplamente diversas em termos de suas necessidades educacionais e sua forma de se expressar e compreender o mundo.

O fato de apresentarem a deficiência visual como característica comum faz com que essa categoria possa incluir, por exemplo, um estudante com baixa visão associada a deficiência física, com uma boa comunicação e expressividade ou um estudante cego, com deficiência intelectual e déficit de comunicação, o qual necessita de uma dedicação exclusiva durante a realização das atividades diárias.

O fato é que as crianças com DMSV não são iguais, por isso não podemos traçar estratégias padronizadas para seu aprendizado. O professor deverá conhecer suas características e necessidades para elaborar uma proposta de trabalho adequada.

\footnotetext{
${ }^{30} \mathrm{Em}$ plena pandemia o Brasil ficou mais de 120 dias sem ministro da saúde, com trocas ministeriais e em uma clara desarticulação entre os governos federal, estaduais e municipais no combate à pandemia.
} 


\section{RevistAleph}

Como se vê, a DMSV é mais que a mera combinação ou associação de deficiências, pois envolve um grupo muito heterogêneo o qual, embora compartilhe alguns atributos específicos, também pode apresentar sua própria singularidade e necessidades (NUNES, 2001; HORN; KANG, 2012). E ainda devemos considerar a dimensão humana para além da deficiência, com suas características afetivas, sociais, culturais, econômicas e familiares que fazem de cada estudante um ser único. Por isso, é essencial conhecê-lo para traçarmos propostas curriculares e estratégias didáticas condizentes com suas necessidades e interesses.

Muitas dessas crianças lutam diariamente para comunicar seus interesses, compreender conceitos e ideias abstratas. A intensidade de suas necessidades pode representar um impacto generalizado no desenvolvimento, fazendo que precisem acessar as informações por meio dos sentidos remanescentes da audição, do olfato, do paladar e, sobretudo, pelo tato (HORN; KANG, 2012). A ausência da visão pode afetar seriamente o desenvolvimento da criança em diferentes dimensões, como por exemplo, a coordenação motora que, em função da falta do estímulo visual, interfere no engatinhar, no ficar de pé, no caminhar e no correr.

Consequentemente, esse atraso influencia na aquisição da autonomia. Resultando em insegurança, medo e dependência de outras pessoas, o que acaba por afetar o seu desenvolvimento global. Crianças com DMSV frequentemente têm limitações motoras, que influenciam em sua postura, locomoção além de limitarem a sua interação social, comunicação intencional e exploração de seu ambiente (HORN; KANG, 2012).

Para muitas dessas crianças, o toque é essencial para a aprendizagem e para a comunicação. Como mencionado anteriormente, com o advento da pandemia da COVID-19, o distanciamento físico foi uma das medidas a serem tomadas para evitar a disseminação da doença. Sem poder sair às ruas e frequentar os diferentes espaços sociais, esses estudantes se limitaram ao convívio familiar em suas residências.

Importa dizer que o processo de aceitação de um filho com deficiência é vivenciado de forma singular pelas famílias. A esse respeito Dantas et al. (2019), investigaram a repercussão da chegada e dos cuidados atribuídos a um filho com 


\section{RevistAleph}

deficiência múltipla na família e elencaram seis aspectos que afetam significativamente a estrutura familiar, são eles:

a) Restrição social: alguns pais, no intuito de protegerem seus filhos dos preconceitos e estigmas da sociedade, evitam sair de casa em função da insegurança em relação ao comportamento do filho. A falta de apoio dos demais membros da família também restringem as relações sociais, pois sobrecarregam os pais;

b) Instabilidade financeira: devido a reestruturação da família para cuidar e dar atenção ao filho, um dos pais acaba deixando de trabalhar para se dedicar ao filho, enquanto o outro acaba tendo jornada integral e serviços extras para dar conta dos custeios de atendimentos e recursos para o filho;

c) Desgaste das relações familiares: os cônjuges passam a não ter tempo de se dedicar na relação a dois, de dar atenção aos demais filhos, e demais familiares;

d) Sentimentos aflitivos: de fracasso e frustração por não terem um filho idealizado e pensarem que os filhos não poderão se casar, viver sozinhos, ter filhos, trabalhar. Os pais sentem medo, ansiedade e angústia pela necessidade de protegerem os filhos em situações de vulnerabilidade;

e) Mudança na dinâmica familiar: situação necessária para atender a todas as demandas do filho;

f) Estresse na saúde e no bem-estar: situação causada pela exaustão mental e física de pais que se dedicam quase que exclusivamente às necessidades diárias de seus filhos, como a busca por serviços adequados e acabam não tendo tempo para si.

Essas questões levantadas no estudo dos autores nos mostram a complexidade e a reestruturação que as famílias passam para conseguirem se adaptar e atender as necessidades da criança com DMSV, situação que no período de pandemia se agrava e se intensifica uma vez que os pais se veem responsáveis também pelo ensino dessas crianças. Quando não recebem orientação e auxílio adequados das escolas, essas famílias precisam se reestruturar, uma vez que alguns desses estudantes necessitam de dedicação e atenção intensa e contínua. 


\section{RevistAleph}

\section{Atividades para estudantes com DMSV em tempos de distanciamento físico}

As famílias e professores de estudantes com DMSV se questionam sobre o que poderiam fazer para dar continuidade ao ensino em tempos de pandemia. Se não houver uma continuidade nos trabalhos desenvolvidos na escola, os estudantes podem deixar de evoluir em vários aspectos e até retroceder em alguns aprendizados.

O trabalho desenvolvido nas aulas de Educação Física, com práticas da cultura corporal, é essencial para conhecimento do corpo, socialização e autonomia na busca de um desenvolvimento integral do estudante.

Schmitt, Zuchetto e Nasser (2016) acompanharam uma criança com encefalopatia crônica não evolutiva e com surdez profunda durante três anos num programa de atividade física adaptada. Estes autores perceberam que, devido à realização regular de atividades físicas, houve melhora motora, cognitiva e social no desenvolvimento dessa criança, pois a mesma conseguiu expressar suas vontades e interesses com maior facilidade.

Geralmente, o primeiro passo consiste em tentar compreender as limitações, a forma de comunicação e o estilo de aprendizagem dessas crianças para melhor propor atividades que valorizem seus pontos fortes (NELSON, 2002). Tais atividades devem levar em consideração o impacto da deficiência visual associada a outras condições, tais como: limitações motoras, dificuldades de comunicação e condições frágeis de saúde. Mas que tipo de atividade pode ser realizada em casa e orientada pelo professor de Educação Física, de modo a valorizar os pontos fortes de um estudante com DMSV?

$\mathrm{Na}$ escola, os professores já sentiam dificuldades em trabalhar com os estudantes com DMSV dentro de uma perspectiva inclusiva. No atual contexto, em que os professores também estão aprendendo a trabalhar à distância, essa prática da cultura corporal orientada se torna mais complexa.

Os professores de Educação Física que se apropriam de estratégias como feedback tátil, audiodescrição de movimentos e modelagem tátil no ensino presencial para desenvolver movimentos com esses estudantes. No atual contexto, à distância, precisa ensinar essas estratégias necessárias aos responsáveis, o que não se reduz a 


\section{RevistAleph}

repassar os conteúdos e atividades a serem desenvolvidas aos familiares, mas quase que uma formação pedagógica.

Sally Rogow (2005) reconhece os inúmeros desafios que se impõe nos caminhos da educação dessas crianças. Essa autora menciona que elas fazem parte de um grupo tão diverso e tão variado em termos de suas dimensões cognitivas, sensoriais e físicas que só com muita atenção às suas necessidades excepcionais de aprendizagem é que se pode iniciar um trabalho efetivo.

Algumas pesquisas (ROWLAND, 1984; ROGOW, 2005; HORN; KANG, 2012) destacam a importância da expectativa, do estímulo e das oportunidades de interação social na educação dessas crianças. Esses estudos valorizam também a criação de oportunidades para que elas explorem e experimentem as diferenças de seus ambientes. De igual modo, é importante lembrar que as atividades sugeridas devem ser planejadas e implementadas de forma colaborativa entre a família e os profissionais da escola.

Essas atividades se baseiam em recomendações que vão do geral ao específico e dão exemplos de materiais de baixo custo que podem ser encontrados dentro de casa. São atividades que podem ser desenvolvidas e reforçadas por professores de diferentes áreas, junto aos saberes específicos de cada disciplina. Dessa forma, propomos aqui algumas atividades que possam ser aplicadas e replicadas de forma colaborativa entre professores, demais profissionais, familiares e o estudante com DMSV no atual contexto de pandemia.

\section{Aprendizagens baseadas na rotina}

A maioria dos eventos diários podem se transformar em rotina. Quer seja escovar os dentes, tomar café da manhã ou ir brincar. As rotinas são um recurso valioso para auxiliar as crianças com DMSV a se organizarem, a desenvolverem conceitos e habilidades a partir de orientações concretas que representam suas atividades diárias (BLAHA; MOSS, 1991). 


\section{RevistAleph}

Luiselli e Bruce (2020) consideram que as rotinas podem e devem ser feitas no ambiente doméstico, pois ajudam as crianças a desenvolverem habilidades de comunicação e favorecem a sua participação em atividades da vida diária; oferecem previsibilidade e segurança emocional para as crianças, pois antecipam o que acontecerá a seguir; dão noção de temporalidade, ou seja, o que vamos fazer agora, a seguir e depois; além de mostrar que as coisas têm um começo, um meio e um fim.

No contexto atual de pandemia, em que a rotina escolar e familiar se reconfigurou, estabelecer uma nova rotina para atividades de ensino e aprendizagem mostra-se essencial, inclusive para as atividades, práticas e vivências específicas da cultura corporal do movimento. A Figura 1 mostra um exemplo de sugestão de rotina para atividades iniciais do dia.

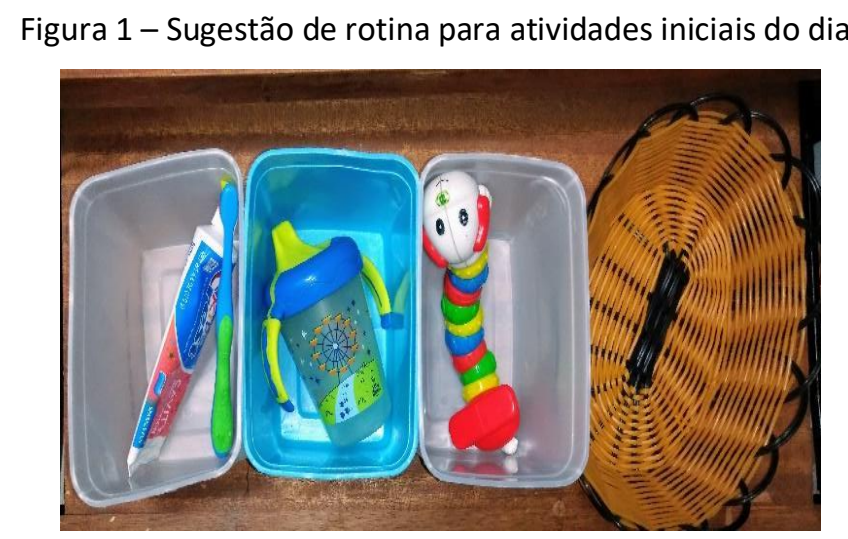

Fonte: Arquivo pessoal.

Da esquerda para direita, a imagem da figura 1 mostra três potes de sorvete retangulares e uma cesta oval. No primeiro pote, de cor branca, há uma escova e uma pasta de dentes infantil; no segundo pote, de cor azul, há um copo infantil com tampa e alças, nas cores azul e amarela; no terceiro pote, de cor branca, há um chocalho segmentado nas cores amarelo, vermelho, branco e verde; ao lado desse pote, há uma cesta de vime bege com contorno preto. Essa cesta funciona como "cesta do acabou".

Para a realização dessa atividade, o adulto pode orientar a mão da criança e explicar o que ela fará assim que acordar. A primeira atividade é escovar os dentes e higiene pessoal. Depois que a primeira atividade terminar, a escova e a pasta de dentes 


\section{RevistAleph}

infantil devem ser colocadas na "cesta do acabou". O mesmo deve ser feito com o copinho e com o brinquedo.

Robie Blaha e Kate Moss (1991) destacam os seguintes aspectos em relação às rotinas:

a) as rotinas devem ter um nome (rotina da manhã, por exemplo);

b) precisam ter um começo, meio e fim muito claros;

c) precisam ter um objetivo (associar objetos a atividades, por exemplo, o copinho representa o lanche);

d) precisam ser repetitivas;

e) devem valorizar a formação de conceitos.

Nesse sentido, as atividades referentes às aulas de Educação Física podem ser estabelecidas em uma rotina de três ou quatro vezes na semana em dias alternados e adaptadas ao ambiente disponível a cada família. O exemplo dado na figura 1 pode ser utilizado para outros momentos do dia e com os objetos disponíveis dentro de casa. Nesse sentido, a figura 2 apresenta outra sugestão de rotina: a rotina da tarde.

Figura 2 - Sugestão de rotina para as atividades da tarde.

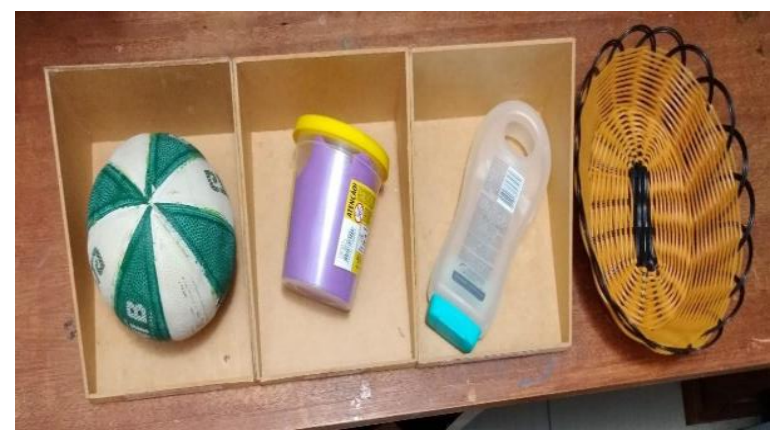

Fonte: Arquivo pessoal.

A imagem da figura 2 mostra três opções de atividades dentro de divisórias feitas com MDF e uma cesta feita de vime para representar a "cesta do acabou". Da esquerda para direita a imagem mostra uma bola, a seguir um pote de massa de modelar na cor lilás, um shampoo e na sequência, a cesta do acabou. Assim como na atividade anterior, o adulto poderá convidar a criança para brincar à tarde e orientar a mão dela para 


\section{RevistAleph}

brincar com bola e ao término dessa atividade, a bola deverá ser colocada dentro da cesta do acabou. O mesmo deverá ser feito com os demais objetos.

\section{Fazendo escolhas em casa}

Oferecer oportunidades para fazer escolhas é, sem dúvida, uma forma de aumentar a independência e melhorar a qualidade de vida de crianças com DMSV. Mas, apesar do consenso apontado em algumas pesquisas (SIGAFOOS; DEMPSEY, 1992; CLARK; MCDONNELL, 2008) sobre a importância de fazer escolhas, ainda é comum que os adultos escolham pelas crianças em função dos mais diferentes motivos, como pressa, descrédito na capacidade da criança escolher por si só, entre outros. A figura 3 mostra uma sugestão de escolha que pode ser feita pela criança com DMSV no momento da alimentação.

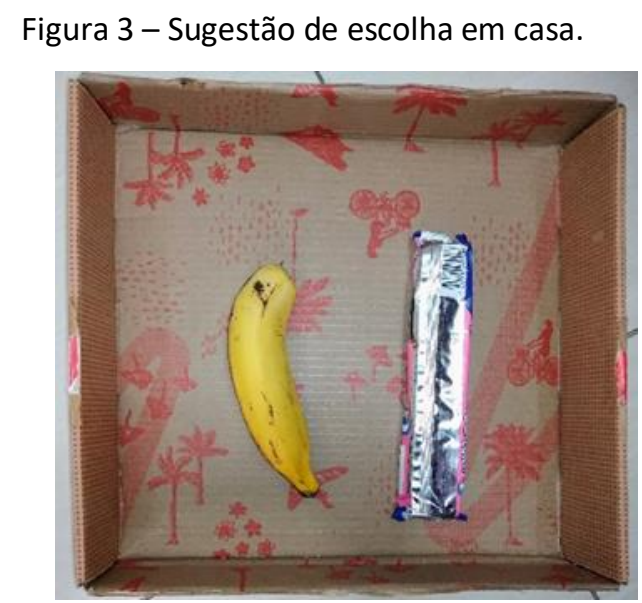

Fonte: Arquivo pessoal.

A imagem da figura 3 mostra uma caixa de papelão com uma banana e um pacote de bolachas recheadas. Para evitar que a criança se perca no espaço, procurando os itens para escolher, deve-se colocá-los dentro de uma área delimitada.

Jeff Sigafoos e Roslyn Dempsey (1995) mencionam que uma das formas de aumentar a tomada de escolhas por crianças com DMSV, consiste em começar sempre por algo do interesse da criança e para que essa seleção seja o mais confiável possível, é importante que isso seja feito, inicialmente, entre dois objetos repetidas vezes. 


\section{RevistAleph}

O exemplo dado na imagem da figura 3, pode ser modificado para ocorrer com outros itens, tais como brinquedos, peças do vestuário, outros alimentos ou, até mesmo, atividades que podem ser representadas por objetos.

No caso da Educação Física, por exemplo, poderiam ser colocados na caixa uma bola, um elástico ou um boneco para conhecimento corporal. Na figura 4 podemos verificar duas opções de escolha, uma bola, que pode representar atividades no campo e, um par de óculos de mergulho, que pode representar atividades aquáticas. Importante lembrar que essas atividades devem levar em consideração as possibilidades de cada residência, por isso a importância da colaboração entre os professores e os familiares.

Figura 4 - Sugestão de escolha em casa para atividades relacionadas à Educação Física.

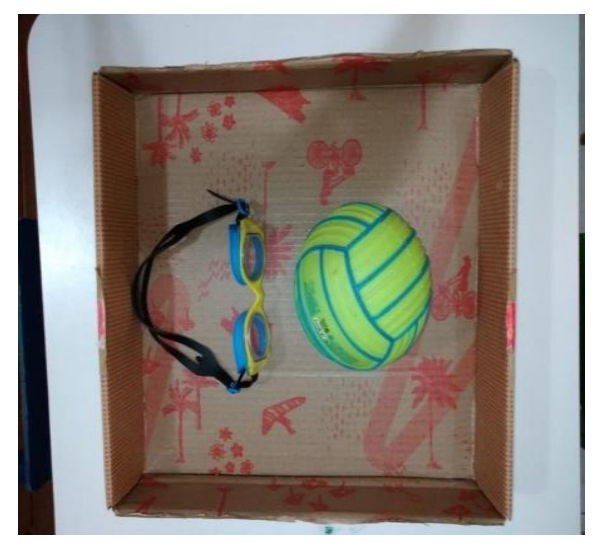

Fonte: Arquivo pessoal.

A imagem da figura 4 mostra uma caixa de papelão com uma bola, na cor amarela com contornos azuis, e um óculos de mergulho infantil. Interessante salientar que esses objetos podem funcionar como "objetos de referência" que servem para simbolizar determinada atividade física ou alguma brincadeira, as quais podem ser escolhidas pelo estudante, conforme seu interesse.

\section{Independência e funcionalidade em tempos de distanciamento}

Apesar do impacto de suas deficiências e do alto grau de suas necessidades, inclusive com implicações educacionais e sociais, ainda assim crianças com DMSV 


\section{RevistAleph}

podem alcançar certa independência por meio de atividades funcionais (VAN DER PUTTEN et al., 2005).

Independência, para esse grupo tão específico de crianças, significa fornecerIhes oportunidades para exercerem controle sobre suas escolhas e sobre seu ambiente. As sugestões de atividades apontadas anteriormente são pontos de partida que permitem que o estudante adquira certa independência por meio de rotinas organizadas e previsíveis e através de oportunidades de fazer escolhas.

Horn e Kang (2012) são eloquentes ao enfatizar que, assim como acontece com todas as crianças, os resultados de aprendizagem para crianças com deficiência múltipla sensorial devem incentivar a curiosidade e se apoiar em na promoção de habilidades, na associação de objetos a atividades e na interação com outras pessoas.

Essas crianças precisam de ajuda e incentivo para se envolver em interações com outras pessoas e para pesquisarem objetos de forma ativa. Nesse sentido, as atividades sugeridas anteriormente se destacam por oferecerem experiências significativas e concretas que se apoiam no contexto natural do ambiente residencial (HORN; KANG, 2012).

\section{Considerações Finais}

Diante das considerações apresentadas anteriormente, concluímos que todas as crianças, inclusive as que apresentam DMSV, têm o direito de terem acesso às estratégias de ensino e aprendizagem adequadas às suas necessidades educacionais específicas.

Suas famílias precisam receber orientações com base em uma proposta colaborativa para organizarem um ambiente doméstico profícuo de habilidades baseadas no uso dos sentidos remanescentes dessas crianças. É interessante salientar que as atividades planejadas e desenvolvidas de forma colaborativa e implementadas pelos familiares não devem ser confundidas com a educação familiar, ou ensino residencial. A prática do chamado ensino remoto é uma realidade de todos os 


\section{RevistAleph}

estudantes e, as atividades aqui descritas buscam facilitar a reorganização de práticas da cultura corporal do movimento durante esse período.

Atividades simples, como serem encorajadas a interagir com os familiares, a usarem suas diferentes modalidades comunicativas para se expressarem com parceiros comunicativos dispostos a compreender seus interesses, a explorar ativamente o ambiente, certamente ampliará a comunicação, sua autonomia e sua autoconfiança em participar ativamente da rotina familiar (NUNES, 2001; HORN; KANG, 2012).

Acreditamos que se as famílias tiverem uma orientação adequada, de modo que possam encorajar a criança a agirem de forma autônoma na sua interação com os familiares e com o ambiente a sua volta, por meio de atividades baseadas no envolvimento ativo, as crianças serão grandemente beneficiadas.

Esperamos que as sugestões de atividades propostas nesse trabalho possam contribuir com a prática pedagógica de professores de Educação Física, principalmente neste momento de distanciamento físico. Que o estabelecimento de rotinas e práticas colaborativas possam aproximar professores, estudantes e familiares em prol de uma educação digna, democrática, participativa e inclusiva.

\section{Referências}

ARGYROPULOS, V.; THYMAKIS, P. Multiple Disabilities and Visual Impairment: An Action Research Project. Journal of Visual Impairment \& Blindness, v. 108, n. 2, 2014.

BERTONI, E. O impacto da campanha 'Brasil não pode parar' de Bolsonaro. Nexo Jornal eletrônico, [s.I], 27 mar. 2020. Disponível em: https://www.nexojornal.com.br/expresso/2020/03/27/O-impacto-da-campanha\%E2\%80\%98Brasil-n\%C3\%A3o-pode-parar\%E2\%80\%99-de-Bolsonaro. Acessado em 04 de junho de 2020.

BLAHA, R.; MOSS, K. Make it a routine. P.S. NEWS!/SEE/HEAR Newsletter, v. IV, n. 3, p. 10-12, 1991.

BOOTH,T.; AINSCOW, M. Index for inclusion - developing learning and participation in schools. Bristol: CSIE, 2000.

BRASIL. Ministério da Saúde. Secretaria de atenção especializada à saúde. Protocolo de manejo clínico da Covid-19 na atenção especializada. Brasília, 2020. 


\section{RevistAleph}

CLARK, C.; MCDONNELL, A. P. Teaching choice to children with visual imparments and multiple disabilities in preschool and kindergarten classrooms. Journal of Visual Impairment \& Blindness, v. 102, n. 7, p. 397-409, 2008.

COVID-19 no Brasil. Dados até 19/09/2020. Site ministério da Saúde. Disponível em: https://susanalitico.saude.gov.br/extensions/covid-19 html/covid-19 html.html. Acesso em 20 de set. 2020.

DANTAS, K. O. et al. Repercussões do nascimento e do cuidado de crianças com deficiência múltipla na família: uma metassíntese qualitativa, Cadernos de Saúde Pública, v. 35, n. 6, p. 119, 2019. Disponível em:

file://C:/Users/afir1/Documents/def\%20multipla\%20e\%20familia\%20repercussoes\%20e\%20c uidados.pdf. Acesso em 3 de out. de 2020.

FREITAS, L. C. Os reformadores empresárias da educação: da desmoralização do magistério à destruição do sistema público de educação. Educação e Sociedade, Campinas, v.33, n.119, p.379-404, 2012.

FUNDAÇÃO OSWALDO CRUZ. Covid-19 - Perguntas e Responstas: o que é o novo coronavírus? Portal Fiocruz, 03 de fevereiro de 2020. Acessado em: 10 de setembro de 2020. Disponível em: https://portal.fiocruz.br/pergunta/o-que-e-o-novo-coronavirus

HORN, E. M.; KANG, J. Supporting young children with multiple disabilities: what do we know and what do we still need to learn? Topics Early Child Special Education, v. 31, n. 4, p. 241-248, 2012.

KEIL, S. Survey of educational provision for blind and partially sighted children in England, Scotland and Wales in 2002. British Journal of Visual Impairment, v. 21, n. 3, 2003.

LEMOS, C. E. C; ASSIS, G. C. de. A pandemia da Covid-19, a exposição das desigualdades e o discurso da necropolítica neoliberal. Revista Ensaios de Geografia, Niterói, v. 5, n. 9, p. 34-39, 2020.

LUISELLI, T. E.; BRUCE, S. Establishing routines at home. Published in National Center on DeafBlindness/Virtual Deaf-Blind Sumit, 29 July, 2020.

MBEMBE, A. Necropolítica. 3. ed. São Paulo: n-1 edições, 2018.

MINAYO, M. C. de S. O desafio do conhecimento: pesquisa qualitativa em saúde. São Paulo: Hucitec, 2014.

MINISTÉRIO DA SAÚDE. O que é COVID-19? Ministério da Saúde. Governo Federal do Brasil. 11 de setembro de 2020. Acessado em: 14 de setembro de 2020. Disponível em: https://coronavirus.saude.gov.br/sobre-a-doenca.

NELSON, C. et al. A framework for understanding young children with severe multiple disabilities: the van dijk approach to assessment. Research \& Practice for Persons with Severe Disabilities, v. 27, n. 2, p. 97-111, 2002. 


\section{RevistAleph}

NUNES, C. Aprendizagem activa na criança com multideficiência: guia para educadores. Lisboa: Ministério da Educação/Departamento da Educação Básica, 2001.

ROGOW, S. A developmental model of disabilities. The International Journal of Special Education, v. 20, n. 2, p. 132-135, 2005.

ROWLAND, C. Preverbal communication of blind infants and their mothers. Journal of Visual Impairment and Blindness, v. 78, n. 7, p. 297-302, 1984.

SANTOS, B. S. A cruel pedagogia do vírus. Coimbra: Almedina, 2020.

SIGAFOOS, J.; DEMPSEY, R. Assessing choice making among children with multiple disabilities. Journal of Applied Behavior Analysis, v. 25, n. 3, p. 747-755, 1992.

SCHMITT, B. D.; ZUCHETTO, A. T.; NASSER, J. P. Influência da Educação Física adaptada inclusiva no desenvolvimento global de uma criança com deficiências múltiplas durante três anos. Cinergis, Santa Cruz do Sul, V. 17, n.1, p. 48-55, 2016. Disponível em:

file:///C:/Users/afjr1/Downloads/7084-34342-1-PB.pdf. Acesso em 3 de out. de 2020.

SILVA, A. P. O professor de educação física como agente do processo inclusivo. In: SANTOS, M. P.; PAULINO, M. M. (Orgs.). Inclusão em educação: culturas, políticas e práticas. 2a ed. São Paulo: Cortez. 2008, p. 69-81.

VAN DER PUTTEN, A. et. al. Children with profound intellectual and multiple disabilities: The effects of functional movement activities. Clinical Rehabilitation, v. 19, n. 6, p. 613-620, 2005.

WHO. World Health Organization. Coronavirus disease (COVID-19) outbreak [Internet]. Geneva: World Health Organization; 2020. Acessado em: 29/08/2020. Disponível em: https://www.who.int/emergencies/diseases/novel-coronavirus-2019

Recebido em: 05/01/2021

Aprovado em: 08/06/2021 